\title{
Weak Function Word Shift
}

\author{
Ralf Vogel, University of Potsdam
}

draft, 28th April 2004

\begin{abstract}
The fact that object shift only affects weak pronouns in mainland Scandinavian is seen as an instance of a more general observation that can be made in all Germanic languages: weak function words tend to avoid the edges of larger prosodic domains. This generalisation has been formulated within Optimality Theory in terms of alignment constraints on prosodic structure by Selkirk (1996) in explaining the distribution of prosodically strong and weak forms of English function words, especially modal verbs, prepositions and pronouns. But a purely phonological account fails to integrate the syntactic licensing conditions for object shift in an appropriate way. The standard semantico-syntactic accounts of object shift, on the other hand, fail to explain why it is only weak pronouns that undergo object shift. This paper develops an Optimality theoretic model of the syntax-phonology interface which is based on the interaction of syntactic and prosodic factors. The account can successfully be applied to further related phenomena in English and German.
\end{abstract}

\section{Introduction}

Weak function words in the Germanic languages have prosodic properties in common that have often been overlooked, especially by syntacticians. Once these properties are taken into account, a number of seemingly very different syntactic phenomena can receive a common explanation. The phenomenon we will mainly address is object shift (OS) in Scandinavian, exemplified in (1). OS has usually been given an explanation in syntactic and/or semantic, especially information structural terms, including the fact that only 'weak' elements can undergo OS. For Swedish, OS of weak pronouns has generally been reported to be optional, while it is obligatory in Danish (cf. Vikner 2001) - the "\%" in (1-a) signals that the clause is dispreferred, but not ungrammatical. Stressed pronouns do not shift.

(1) Weak pronoun object shift in Swedish:

a. Jag kysste henne inte (\%henne)

I kissed her not (*her) 


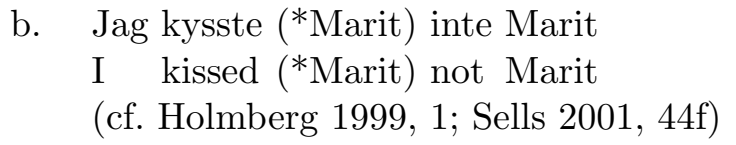

One problem with an account in terms of information structure is that $(1-a, b)$ can be used in the same context under the same information structural conditions, for example, as an answer to the question "Did you kiss Marit?". It is therefore very likely that the contrast does not reflect a semantic difference. I will discuss this problem in more detail in section 2 .

Selkirk (1996) deals with the ban on weak forms of function words in phrasefinal positions in English, as exemplified in (2):

$$
\begin{aligned}
& \text { I can eat more than Sara cán } \quad \text { [kæn], * [kən], *[kn] } \\
& \text { (Selkirk 1996, 200) }
\end{aligned}
$$

Selkirk argues that this ban is due to the prosodic deficiency of (especially monosyllabic) weak function words: they lack word stress and therefore do not constitute prosodic words. They are either reduced, or, if they are syllabic, then they are schwa syllables and therefore cannot bear stress.

English also displays an interesting restriction on the placement of pronouns which is reminiscent of the Scandinavian facts, as shown with the minimal pair in (3).

$$
\text { I gave up the plan } / *_{\text {it }} \text { I gave the plan/it up }
$$

An obvious counterexample like "I like it" in fact shows the parallelism. OS in Scandinavian is limited to cases where the verb and other material usually preceding the weak pronoun are moved out of VP. This fact is known as 'Holmberg's generalisation' - it will be discussed in more detail in section 2. Weak pronouns in final positions in both English and Scandinavian are thus unacceptable only if there is a syntactically legitimate alternative structure.

Like Swedish, German avoids weak pronouns to the right of adverbs. This can be observed with both object and subject pronouns:

(4) German object pronouns:

a. Warum liest Peter (es) nie (*es)?

Why reads $\mathrm{P} . \quad$ (it) never $(*$ it $)$ ?

(Vikner 2001, 323)

b. Warum liest Peter (das Buch) nie (das Buch)

Why reads P. (the book) never (the book)

(5) German subject pronouns:

a. Heute wird $*$ bestimmt es regnen $/ \sqrt{ }$ es bestimmt regnen today will certainly it rain/ it certainly rain 
b. Dann hat wohl *er/ ER gelogen

then has well *he/ [he] FOC lied

c. Dann hat (Peter) wohl (Peter) gelogen

then has (Peter) well (Peter) lied

The ban on weak subject pronouns to the right of adverbials has also been reported for Swedish, as exemplified in (6).

(6) Swedish subject pronouns:

a. Igår tog inte Kalle med sig sina pengar

yesterday carried not $\bar{K}$. with SELF his money

b. Igår tog inte *han/HAN med sig sina pengar

c. Igår tog han inte med sig sina pengar

(Hellan and Platzack 1995, 50)

In Schmid and Vogel (2004), we present data from the German dialect of Upper Hessia where the present perfect auxiliaries built of 'haben' ('have') are true weak function words. They cannot be stressed, and they may not occur clause-finally in 3 -verb clusters:

(7) Upper Hessian, German dialect from the region about 30-100 km north of Frankfurt/Main, (cf. Schmid and Vogel 2004):

weil er es Lied (hot/*HOT) singe (hot/*HOT) misse/gemisst because he the song (has/*HAS) sing (has/HAS) must-INF/-PART.

$\left({ }^{*}\right.$ hot $\left./{ }^{*} \mathrm{HOT}\right)$

$\left({ }^{*}\right.$ has $\left./{ }^{*} \mathrm{HAS}\right)$

We attribute this effect to a constraint we call *WeAkFinal. Citing Selkirk's (1996) work on weak function words in English, we elaborate an account of these facts very much along the lines of what I will pursue here.

I will argue in this paper that these facts have a common source, namely the ban on weak function words at edges of prosodic domains, as observed for English by Selkirk (1996). In section 3, I will discuss her approach in more detail. We will see that it needs to be enriched by syntactic constraints to correctly predict object shift. In section 4, I will propose an Optimality theoretic model of the syntaxphonology interface where Selkirk's prosodic constraints interact at a level playing field with syntactic constraints on the linearisation of syntactic elements. I will then show how this account derives the pronoun facts in mainland Scandinavian, English and German.

\section{Object Shift}

From the generative syntactic literature, one can easily get the impression that object shift is a quite idiosyncratic feature of the Scandinavian languages. But 
as suggested in section 1, this might be a matter of perspective. Our point of departure is the fact that not all NP objects undergo object shift in the mainland Scandinavian languages, but only weak pronouns. This is exemplified with the Danish examples in (8).

(8) Object shift in Danish:

a. *Hvorfor læste Peter aldrig den?

b. Hvorfor læste Peter den aldrig ?

Why read P. (it) never (it)

c. Hvorfor læste Peter aldrig den her bog ?

d. *Hvorfor læste Peter den her bog aldrig ?

Why read P. (this book) never (this book)

(Vikner 2001, 321)

(8-a) shows that a weak pronoun following an adverbial is ungrammatical in Danish. The pronoun has to precede the adverb (8-b). With a full NP like 'den her bog' it is the other way around.

The Swedish examples in (9) show that application of object shift is restricted to cases where the object is adjacent to an adverb. Whenever the object would have to cross other material, like the verbal participle in $(9-\mathrm{a}, \mathrm{b})$, object shift is not allowed. ${ }^{1}$

(9) Weak object pronoun shift in Swedish:
a. *Jag har henne inte kysst
I have her not kissed
b. Jag har inte kysst henne
I have not kissed her
c. Jag kysste henne inte
I kissed her not
d. \%Jag kysste inte henne
I kissed not her

(Swedish, Holmberg 1999, 1; Sells 2001, 44)

That not only the verb, but any VP-internal element may block object shift, is illustrated in (10):

Swedish, OS blocked:
a. *Jag talade henne inte med $t_{i}$
I spoke her not with

\footnotetext{
${ }^{1}$ Many of the Swedish examples have first been introduced by Holmberg (1986). Sells (2001) gives an excellent overview of the discussion since that seminal work, and documents most of the Swedish OS facts that have been reported and discussed in the meantime.
} 


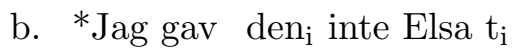
I gave it not Elsa

c. *Dom kastade mej $j_{i}$ inte ut $t_{i}$

They threw me not out

(Holmberg 1986; Sells 2001, 47f)

In each of these cases, the pronoun has to stay within VP, in the position indicated by the trace. This observation is the core of 'Holmberg's Generalisation' (Holmberg 1986). More recently, Holmberg (1999) formulated it as a surface filter:

Holmberg's generalisation (Holmberg 1999, 15):

Object Shift cannot apply across a phonologically visible category asymmetrically c-commanding the object position except adjuncts.

Not only object pronouns shift. Josefsson (2003), following Hellan and Platzack (1995), shows that subcategorised pronominal adverbials behave the same in Swedish: ${ }^{2}$
a. Därför bor Sten $\left(*_{\mathrm{i}}\right.$ Lund) inte i Lund längre therefore lives Sten (*in Lund) not in Lund anymore
b. Därför bor Sten (där) inte där längre therefore lives Sten (there) not there anymore

This observation calls the traditional syntactic explanation of OS into question. Starting with Holmberg (1986), many researchers ${ }^{3}$ assumed that OS is driven by case, and in particular, that the landing site of OS is the position where the object receives case. Such an explanation would not carry over to (12-b), unless one claims that the adverbial pro-form "där" needs to be assigned structural case - a counterintuitive stipulation under which we would lose other important distinctions, for instance that between structural case and oblique forms.

Holmberg (1999) adds another important observation that to him renders the explanation of OS in terms of case theory untenable. If the structure in (13-a) is derived purely syntactically, then, under standard assumptions, it cannot be derived without violating cyclicity:

(13) OS and verb fronting:

a. Kysst har jag henne inte (bara hållit henne i handen) kissed have I her not (only held her by the hand)

b. *Kysst har jag Marit inte

\footnotetext{
${ }^{2}$ A well-known difference between the Scandinavian languages is that OS is optional in Swedish, as mentioned by many authors, and as recently shown in an empirical survey by Josefsson (2003). Danish, as reported by Vikner (1995), is much more strict - if OS is possible, it is obligatory.

3 An incomplete list includes Chomsky (1993); Vikner (1994); Holmberg and Platzack (1995); Bobaljik (1995); Broekhuis (2001); Bobaljik (2002).
} 
c. ?Kysst har jag inte Marit

(Holmberg 1999, 7ff)

Summing up Holmberg's detailed argumentation very roughly: if OS in (13-a) has applied after the verb has moved to the front, then OS is a counter-cyclic operation. If the fronting of the verb is VP movement, a standard assumption, then the object must have left the VP before VP fronting, violating Holmberg's generalisation. If it does not leave VP, it has to move along with the verb:

Kysst henne har jag inte

(14) is also grammatical. The question is, why? If the trigger for OS is the pronoun's need to be assigned case in a functional projection on top of VP, then it might not be assigned case in (14), and (14) should be blocked by (13-a) because in the latter case the pronoun receives case. However, a standard assumption is that the pronoun is assigned case in situ in structures like (14), by V. But then, why is (13-a) possible? Holmberg concludes that the verb fronting in (13) is an instance of head movement.

The assumption of head movement to a non-head position is problematic in itself. However, as it stands, it seems to be the only way to have OS in (13-a) without violating Holmberg's generalisation, a constraint of which we know that it holds. But if (13-a) is derived by head movement of the verb to [Spec, CP] followed by movement of the pronoun in front of the negation, then this latter step is counter-cyclic, because it targets a node that is below the top node of the syntactic tree, and therefore violates Chomsky's (1993) 'Extension Condition'.

The Extension Condition:

Substitution operations always extend their target.

Chomsky (1993)

Holmberg argues that given the Extension condition OS cannot be substitution, and hence cannot be case movement. It is either adjunction (as argued by Holmberg and Platzack (1995)), or a PF operation. Under both analyses, OS is not an operation of syntax proper, it applies post-cyclically.

Derivation of (13) according to Holmberg (1999):

Step 1 - V-fronting as head movement into an XP position:

$\left[\mathrm{CP} \mathrm{V}_{\mathrm{i}}\left[\mathrm{C}^{\prime} \mathrm{C}^{0} \ldots\right.\right.$ inte $\left.\left.\left[\mathrm{vP} \mathrm{t}_{\mathrm{i}} \mathrm{OBJ}\right]\right]\right]$

Step 2 - Object shift as post-cyclic movement:

$$
\left.\left[\begin{array}{lllll}
\mathrm{CP} & \mathrm{V}_{\mathrm{i}}\left[\mathrm{C}^{\prime}\right. & \mathrm{C}^{0} \ldots \mathrm{OBJ}_{\mathrm{j}} \text { inte }\left[\mathrm{vP}_{\mathrm{i}} \mathrm{t}_{\mathrm{i}} \mathrm{t}_{\mathrm{j}}\right.
\end{array}\right]\right]
$$

Object shift is part of "Stylistic Syntax", as Holmberg calls it. Stylistic syntax operates on the output of 'Formal syntax' which includes merge and move operations, as well as the checking of abstract features. After completion of Formal syntax, phonological features, 'p-features', are inserted. A second cycle of syntac- 
tic operations starts. They are triggered by licensing needs of those p-features. In Stylistic Syntax, the extension condition no longer holds. OS in this approach is adjunction of the moved object triggered by its p-feature.

Holmberg claims that the p-feature in case is $[ \pm$ Foc $]$, a specification whether the item in question is part of the focus or not. Weak pronouns are obligatorily $[-$ Foc $]$, full NPs can be $[+$ Foc $]$ or $[-$ Foc $]$. The licensing of $[-$ Foc $]$ elements works as follows:

"There is a condition that a [-Foc]-marked object (typically a weak pronoun) must be governed by a $[+$ Foc $]$ marked category. Verbs, prepositions and particles are inherently [+Foc], and therefore license a [-Foc]-marked object. A DP is optionally $[+\mathrm{Foc}]$, and is therefore also capable of licensing a $[-$ Foc] argument governed by it (for instance in the double object construction). [...]

If the p-features of a verb chain target the head of the chain (in I, or $\mathrm{C}$, or specCP) the verb trace in VP cannot license a [-Foc]-marked object. If there is no other [+Foc]-marked category governing the object in VP, the object has to move to a position where it is governed by [+Foc], usually adjacent to the moved verb or the subject."

(Holmberg 1999, 36)

The division of syntax into an 'opaque' Formal cycle that is subject to rigid derivational principles, and a stylistic cycle that could in principle override any result of Formal syntax, might raise a number of worries that I will not touch upon here. But the account makes some further problematic assumptions that are more intimately related to the phenomenon.

First, what is the nature of the 'Foc' feature? Holmberg $(1999,23)$ assumes the partition of clause structure that has been proposed by Diesing (1992): VP is the focus domain of the clause, material outside VP belongs to the "presupposition domain'. Thus, the feature is clearly semantically motivated, and refers to information structural properties. One objection against such a view is the fact that the asymmetry between full NPs and weak pronouns remains under identical information structural conditions. This has already been shown in Vikner's (2001) example (8) from Danish, repeated below:

$$
\begin{aligned}
& \text { Object shift in Danish }(=(8)) \text { : } \\
& \text { a. Hvorfor læste Peter }(\text { den }) \text { aldrig }\left(*^{\text {den }}\right) \text { ? } \\
& \text { Why read P. (it) never }\left(*_{\mathrm{it}}\right) \\
& \text { b. Hvorfor læste Peter }\left({ }^{*}\right. \text { den her bog) aldrig (den her bog)? } \\
& \quad \text { Why read P. (*this book) never (this book) } \\
& \text { (Vikner 2001, 321) }
\end{aligned}
$$

These questions can be uttered within the same context. The NPs 'den' and 'den her bog' could refer to the same entity. But still, OS would be ruled out for the 
full NP. This is not to say that it is impossible to state Holmberg's account in an empirically correct way. But given examples like (17), it seems counterintuitive to me that the feature that drives OS reflects the information structural notion of focus. Holmberg himself admits later in the paper that his theory

"[...] is even more like the theory proposed by Hellan (1994). Discussing object shift of weak pronouns, Hellan argues that it is a form of phonologically motivated clitic movement: The weak pronoun needs to cliticise phonologically to a lexical category, but cannot cliticise to an adjunct. [...]"

(Holmberg 1999, 27)

Holmberg's objection against such a phonological approach is that it fails to account for object shift of full NPs in Icelandic. But this is only a failure, if one assumes that weak pronoun OS in mainland Scandinavian and OS in Icelandic have the same single cause. This need not necessarily be so.

OS is optional for Icelandic full NPs, with the interpretive effect that nonspecific indefinite NPs may never shift, while shifted indefinite NPs are necessarily interpreted as specific (see Vikner 2001, for a detailed discussion). Hence, the most natural assumption for Icelandic would be that OS is triggered by the semantic feature $[ \pm$ specific]. Specificity is independent of information structure, as the English example in (18) shows.

\section{A: Who reads books? \\ B: JOHN reads books}

The specificity of 'books' does not change from A to B, while its information structural status might change from NEW to GIVEN.

The trigger for OS must be different in mainland Scandinavian, as only weak pronouns undergo OS, but definite NPs, which are also [+specific], do not. Another argument that (Holmberg 1999, 31) puts forward is:

"The most compelling argument, though, in favour of a unified theory of full DP shift and pronoun shift is that both are subject to $\mathrm{HG}$ [Holmberg's generalisation, R.V.], in exactly the same way"

This argument is only valid if one assumes that the conditions that constrain a syntactic operation and the trigger for that operation are identical. I do not see the need for this assumption and there are numerous examples to the contrary.

Holmberg invents a licensing mechanism for weak pronouns that seems purely stipulative to me. Why should a [-Foc] element need to be licensed by a $[+$ Foc $]$ element in the first place? What does licensing mean in this case? If licensing implies c-command, as Holmberg suggests, then the correlation with focus is even more irritating, as usually focused material is clause-final, i.e., it is much more likely that non-focused material c-commands focused material than the other way around. 
Furthermore, it has been reported for Swedish that a pronoun need not necessarily shift to the immediate right of a verb or argument. (19) is a case of "adverbial intermingling". It has been presented by Hellan and Platzack $(1995,56)$. According to them, the weak pronoun may occur in each of the indicated positions in Swedish:

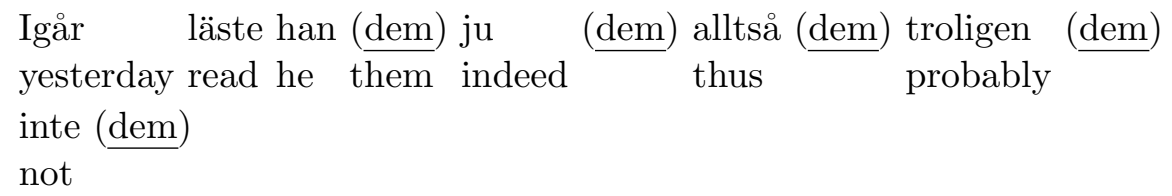

The same objections have to be made concerning a recent proposal by ErteschikShir (2002). Essentially, she proposes a clitic analysis for OS: the weak pronoun cliticises onto the verb and is carried along with it when the verb performs verbsecond movement. Another empirical argument against such an approach has already been given by Hellan (1994) for Norwegian: in yes-no questions verb and object pronoun are not adjacent.

Kyssede Anne ham ikke?

kissed A. him not?

(Danish yes no-question Hellan 1994, 55)

Erteschik-Shir argues that this structure is derived by cliticisation of the pronoun to the subject. If this is possible, one might wonder why it is impossible in simple declaratives, like (21):

\section{*Anne ham kyssede ikke}

A. him kissed not

The problem in both approaches seems to me that an essentially phonological phenomenon is treated syntactically. The constraint on weak pronouns does not seem to be that they have to appear in a particular position or adjacent to particular elements. They only may not appear in a particular position, namely, to the right of a clause-final adverb.

Another example in case is the phenomenon of "long object shift". Sometimes, weak object pronouns might even shift across the subject:

Long object shift in Swedish:

Därför ger mig Tutanchamons hemska förbannelse ingen ro therefore gives me Tutankhamen's terrible curse no peace (Josefsson 1992, 65)

For those examples, Erteschik-Shir again claims that the weak pronoun has cliticised to the subject, this time on its left side. However, the example in (23), a combination of "adverbial intermingling" and long object shift, calls such an account into question: 
(23) Nu mangar (oss) ju (oss) inte längre (oss) någon myndighet att äta sex till åtta brödskivor om dagen

Now urges (us) ass-you-know (us) not (us) longer (us) any authority to eat six to eight slices of bread per day

"We are no longer urged by any authority to eat six to eight slices of bread per day."

(Holmberg and Platzack 1995, 156f)

Here, the subject is a negative polarity item that needs to remain to the right of the negation. For the weak pronominal object to leave the right edge, it has to move across the subject. We not only see that this is possible, but that it can also move further to the left in front of one or more adverbs.

Erteschik-Shir herself admits that an analysis in terms of metrical structure might be necessary to explain the case where the pronoun 'oss' is between the adverbs. But if such an analysis is necessary here, why should it not be exploited for the other cases, too?

To sum up, the licensing feature for weak pronoun OS, called $[ \pm$ Foc] by Holmberg, is very unlikely to be a semantic feature. As Holmberg himself already suggests, the phonological properties of weak pronouns as such seem to be crucial here, in particular their lacking of word stress.

Instead of looking for a phonological theory of weak pronouns, however, Holmberg and Erteschik-Shir are sort of "reinventing the wheel" when proposing a syntactic licensing mechanism. One such phonological account has been developed by Selkirk (1996). It will be the topic of the next section.

\section{The prosodic account by Selkirk (1996)}

Selkirk (1996) deals with an interesting prosodic restriction on English function words:

"[...] in English, monosyllabic function words may appear in either a stressless "weak" form or a "stressed" form, depending on their position in the sentence, whereas a lexical category word always appears in a stressed unreduced form. [...]"

(Selkirk 1996, 187)

As a consequence, lexical words always constitute prosodic words (PWd), while this is optional for function words. Selkirk gives the following four possibilities for function words - 'PPh' stands for 'phonological phrase'.

(24) Possible prosodic realisations of English monosyllabic function words (Selkirk 1996, 188):

i. Prosodic word: $\left((f n c)_{\mathrm{PWd}}(\text { lex })_{\mathrm{PWd}}\right)_{\mathrm{PPh}}$ Prosodic clitics: 


$\begin{array}{lll}\text { ii. } & \text { free clitic } & \left(\text { fnc }(\text { lex })_{\mathrm{PWd}}\right)_{\mathrm{PPh}} \\ \text { iii. } \quad \text { internal clitic } & \left((\text { fnc lex })_{\mathrm{PWd}}\right)_{\mathrm{PPh}} \\ \text { iv. } \quad \text { affixal clitic } & \left(\left(\text { fnc }(\text { lex })_{\mathrm{PWd}}\right)_{\mathrm{PWd}}\right)_{\mathrm{PPh}}\end{array}$

Stressed function words project a PWd. Unstressed ones can be free clitics, integrating into a $\mathrm{PPh}$, internal clitics, integrating into a $\mathrm{PWd}$, or affixal clitics, where they are kind of adjuncts to prosodic words. Selkirk prefers a free clitic analysis for most function words. An affixal clitic analysis is necessary in her account of English weak pronouns. From a conceptual point of view, affixal clitics are problematic: weak function words by definition lack the ability to take part in prosodic structure building. If this is so, how can they cause the recursion of a PWd boundary? We will see below that an affixal clitic analysis can be avoided if syntactic factors are taken into account.

Prosodic structure is hierarchically organised. Utterances ('Utt') are built of and headed by intonational phrases ('IP'), these are built of and headed by phonological phrases, the next lower levels are prosodic word, foot (' $\mathrm{ft}$ ') and syllable $(\sigma)$. Selkirk proposes a number of optimality theoretic i.e., violable constraints on prosodic structure:

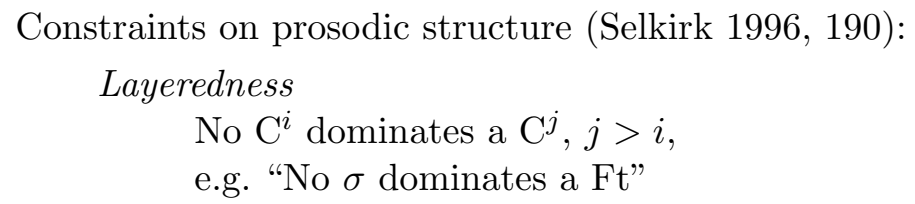

Any $\mathrm{C}^{i}$ must dominate a $\mathrm{C}^{i-1}$ (except if $\left.\mathrm{C}^{i}=\sigma\right)$,

e.g. "A PWd must dominate a Ft"

\section{Exhaustivity}

No $\mathrm{C}^{i}$ immediately dominates a constituent $\mathrm{C}^{j}, j<i-1$,

e.g. "No PWd immediately dominates a $\sigma$ "

Nonrecursivity

No $\mathrm{C}^{i}$ dominates $\mathrm{C}^{j}, j=i$, e.g. "No $\mathrm{Ft}$ dominates a $\mathrm{Ft}$ "

The examples in (26) show that the strong version of function words is required at the right edge of a larger prosodic domain:
a. I can eat more than Sara cán
b. Wherever Ray is, he's having a good time
$[\mathrm{k} n], *[\mathrm{k} ə \mathrm{n}], *[\mathrm{kn}]$
c. What did you look át yesterday?
$[\mathrm{Iz}], *[\mathrm{z}]$
d. Who did you do it fór that time?
[æt], *[ət]
$[\mathrm{for}], *[\mathrm{fr}]$

(Selkirk 1996, 200)

The italicised function words all occur in their strong versions. While the first instance of ' $c a n$ ' in (26-a) is preferably weak, its second occurrence must not be weak. Here, it is in clause-final position. The positions of the other italicised words in (26-b-d) are not clause-final, but they are final in their phonological phrases. 
These observations lead to the assumption of another constraint on prosodic structure that requires the right edge of a phonological phrase to be aligned with the right edge of a prosodic word:

Phonological phrase alignment (Selkirk 1996, 202):

$\operatorname{Align}(\mathrm{PPh}, \mathrm{R} ; \mathrm{PWd}, \mathrm{R})$ (= AlignPPh)

Selkirk further introduces constraints that favour lexical words to project prosodic words and prosodic words to be headed by lexical words. These constraints, together with what was introduced above, derive the following features of English prosodic phonology:

- Prosodic Words tend to be built of lexical categories

- Strong forms of function words occur if the function word

- is isolated

- is focused

- is at the edge of a phonological phrase

Weak forms of function words are seen as instances of free clitics. They do not project prosodic words, nor are they integrated into other prosodic words, rather they are sort of "floating" within phonological phrases.

In principle, such a treatment should also be possible for pronouns, and it appears to be quite attractive to view weak pronouns in Scandinavian as free clitics.

Selkirk does not discuss these cases, but she recognises a problem that occurs with English pronouns. Contrary to the modal verbs, copula verbs and prepositions in (26), weak pronouns can optionally occur clause-finally:

We need'm (= 'need him/them')

(Selkirk 1996, 204)

The constraint ALIGNPPh plays a prominent role in explaining the behaviour of prepositions, modals and copulas. But this now becomes problematic, as it incorrectly predicts that the pronoun must project a prosodic word in (28). Selkirk suggests the following way out of this dilemma: pronouns can be affixal clitics. She motivates this move with the phenomenon of 'intrusive $-r$ ' in Eastern Massachusetts dialects, as observed by McCarthy $(1991,1993)$. He showed that the ' $r$ ' occurs at the right edges of prosodic words, as in (29-a).
a. He put the tuna-r on the table
b. I'm gonna $\left({ }^{*}-r\right)$ ask Adrian
c. I saw ya- $r$ and asked about it

Example (29-b) shows that the right boundary of a weak function word does not license intrusive ' $r$ '. However, in (29-c), we have it after a weak pronoun. 
Therefore, Selkirk assumes that we have the right boundary of a prosodic word here. Because the weak pronoun is unstressed and therefore does not project a prosodic word itself, we must assume a layered structure with a recursive PWd boundary:

$$
\text { ((saw ) Pwd ya ) PWd }
$$

Three objections to this analysis suggest, to my mind, that the picture Selkirk draws is at least incomplete. First, the evidence in (29-c) might also support a free clitic analysis, as the ' $r$ ' also appears at the right boundary of a phonological phrase here, and the example might simply show that intrusive ' $r$ ' can also appear at phonological phrase boundaries.

It is, in fact, impossible to decide whether the ' $-r$ ' is possible because it is at the right edge of a $\mathrm{PWd}$, or because it is at the right edge of a $\mathrm{PPh}$. $\mathrm{PPh}$ are usually right-aligned with PWds, and we know independently that right PWd boundaries license ' $r$ '. If ' $r$ ' was impossible in (29-c), this would be evidence in favour of a free clitic analysis and for the claim that ' $-r$ ' requires a right PWd boundary. But both scenarios are compatible with the possibility of ' $-r$ ' in (29-c).

The second objection concerns the concept of affixal clitics. Weak function words lack prosodic structure. Therefore, they do not take part in prosodic structure building. However, the recursion of a prosodic word boundary, to my mind, is an instance of prosodic structure building, and I wonder how this can be triggered by prosodically invisible material.

The third concern that I have is empirical. The data in (31) are not discussed by Selkirk:
a. I gave up the plan/*it
b. I gave the plan/it up
c. I gave the book/it to Mary
d. I gave Mary the book/*it

If recursion of prosodic word boundaries is possible in the case of (28), why is it impossible here? An explanation of this along Selkirk's lines would end up in the stipulation that this is only possible with verbs, but not with particles or nouns, although these bear the main stress in (31).

What would be an alternative explanation of (28)? First of all, it might not be accidental that Selkirk's standard examples are modal verbs and prepositions, categories which are somewhat between lexical and functional. Pronouns and determiners are much more paradigmatic instances of function words. Perhaps the possibility of shifting freely between a strong and a weak form is special of prepositions and modals, due to their hybrid status.

True function words are preferably weak and cannot shift that freely between weak and strong. Another striking feature of Selkirk's analysis is that it is based on the assumption that AlignPPh is inviolable in English. This might not be so, 
and (28) might simply be an example in case. Under this assumption we could retain the free clitic analysis for all instances of weak function words in English, and would not have to make use of the questionable concept of affixal clitics.

Why, then, is (28) the optimal structure? Well, as the pronoun cannot be stressed, being a true function word, the only way to avoid a violation of AlignPPh would be moving it away from the right edge. This would result in a structure like (32):

*We him need

But this clause is ill-formed for syntactic reasons. The relevant syntactic constraint obviously has higher priority. The formulation of this syntactic constraint will in the end be very similar to Holmberg's generalisation: an object may not move in front of the verb. In (31), however, there are syntactic alternatives that avoid movement of the object in front of the verb. This makes it possible to avoid violating AlignPPh, and therefore structures (31-a,d) are blocked for the weak object pronoun.

To sum up, the integration of a syntactic perspective helps simplifying Selkirk's analysis and avoids some of its problematic aspects. On the other hand, we can integrate the core of Selkirk's analysis, the constraint ALIGNPPh, into a syntactic account of object shift, for example, as a replacement of the problematic $[ \pm$ Foc $]$ feature of Holmberg (1999). Thus, by integrating a syntactic and a phonological perspective it will be possible to get rid of a number of otherwise perhaps unavoidable problematic assumptions. The details of this account are at issue in the next section.

\section{An OT model of the syntax-phonology interaction}

In Vogel (2004, to appear) and Schmid and Vogel (2004), we propose an architecture for Optimality Theoretic syntax that is based on correspondence. The constraint set mainly consists of constraints that regulate the correspondence of semantic, syntactic and phonological structure. Following current thinking in generative syntax (cf. Kayne 1994), linear order is assumed to be part of the surface structure only, and therefore specified in the phonological representation. We will use a simplified version of such a correspondence theoretic OT grammar.

It will be sufficient for our purposes here, to use a model that has syntactic structures $\mathrm{S}$ in the input and pairs of syntactic structures and phonological structures $[\mathrm{S}, \mathrm{P}]$ in the output.

OT model for syntax-phonology interaction:

\begin{tabular}{c|l}
\hline input & syntactic structure $\left[\mathrm{S}_{I}\right]$ \\
\hline $\begin{array}{c}\text { output } \\
\text { candidates }\end{array}$ & syntax, phonology $\left[\mathrm{S}_{O}, \mathrm{P}\right]$ \\
\hline
\end{tabular}


The double occurence of syntax in input and output opens the possibility to let purely syntactic constraints still take effect, such that one syntactic structure can be blocked by another one. This will be necessary for our treatment of the English dative alternation.

In Schmid and Vogel (2004), we propose constraints that regulate the translation of syntactic strucures into strings of words. For example, the relative ranking of the two constraints in (34) determines whether a language is an SVO- or an SOV-language. The definitions in (34) are adapted to our terminology.

\section{a. MAP(complement before head) (MAPch)}

If $\mathrm{A}$ and $\mathrm{B}$ are sister nodes at $\mathrm{S}$, and $\mathrm{A}$ is a head and $\mathrm{B}$ is a complement, then the correspondent of $\mathrm{B}$ precedes the one of $\mathrm{A}$ at $\mathrm{P}$.

b. MAP(head before complement) (MAPhc)

If $\mathrm{A}$ and $\mathrm{B}$ are sister nodes at the $\mathrm{S}$, and $\mathrm{A}$ is a head and $\mathrm{B}$ is a complement, then the correspondent of $\mathrm{A}$ precedes the one of $\mathrm{B}$ at $\mathrm{P}$.

In order to make these constraints applicable, we need to clarify what corresponds. I will assume that only the overt material is taken into account. In particular, only the heads of movement chains are evaluated. Consider the verb second structure in (35), a typical object shift configuration:

$$
\left.\left[{ }_{I_{i}} \mathrm{NP} \mathrm{V}_{\mathrm{j}}\left[\mathrm{VP} \text { NEG [VP } \mathrm{t}_{\mathrm{j}} \mathrm{NP}_{\mathrm{k}}\right]\right]\right]
$$

The P correspondent of VP can only be the material that corresponds to heads of chains within VP, i.e., the $\mathrm{P}$ correspondent of $\mathrm{NP}_{\mathrm{k}}$. The adjoined negation does not belong to the lower segment of VP, but it does belong to the higher segment. Truckenbrodt (1999) argues that only the lower segment of an adjunction structure counts in syntax-prosody mapping. I will follow this assumption here. However, the decision does not bear on the issue, all we need is being able to evaluate the relative order of adjuncts and their hosts.

A second question is which objects in $\mathrm{P}$ can correspond to elements of $\mathrm{S}$. We could simply assume that all words correspond to syntactic objects. On the other hand, there are simple and complex objects in S, in particular, heads and phrases. Likewise, at $\mathrm{P}$, we have words, prosodic words, phonological phrases, and intonational phrases. Truckenbrodt (1999) assumes the following "XP-to-P Mapping Condition":

XP-to-P Mapping Condition (Truckenbrodt 1999, 221):

Mapping constraints relate XPs to phonological phrases, but do not relate XPs to other prosodic entities.

The constraints Truckenbrodt has in mind here are first of all his mapping constraints STRESSXP and WrAPXP, which will be introduced briefly below. However, even if there is no constraint that relates, for instance, prosodic words and 
XPs, it is still important that prosodic words are constituents of phonological phrases, and might correspond to the constituents of an XP. Furthermore, we might not need a mapping constraint for syntactic $\mathrm{X}^{0}$ categories, but might have to determine which elements of $\mathrm{P}$ they correspond to. The S-P correspondence conventions that I assume in this paper are given in (37).

\begin{tabular}{l|l} 
S-P correspondence relations: \\
\hline $\mathbf{S}$ & $\mathbf{P}$ \\
\hline $\mathrm{X}^{0}$ & a (lexical or functional) word. \\
$\mathrm{XP}$ & $\begin{array}{l}\text { the word that corresponds to the head of XP plus the } \\
\text { prosodic words and phonological phrases that correspond } \\
\text { to specifier and complement of XP. }\end{array}$ \\
\hline
\end{tabular}

The P-correspondent of a head is a word. The P-correspondent of an XP contains the correspondent of its head plus the prosodic words and phonological phrases that correspond to the constituents of XP. This assumption has an important consequence for our discussion of object shift. Consider a VP that contains only a weak pronoun in object position, and the traces of verb and subject which have left VP:

$$
\left[\mathrm{vP} \mathrm{t}_{\mathrm{Subj}} \mathrm{t}_{\mathrm{V}}\left[\mathrm{NP} \mathrm{PRO}_{w k}\right]\right]
$$

The traces do not count at all, by assumption. But the weak pronoun does not project a prosodic word, and therefore does not count as correspondent of VP either, according to the conventions in (37). Thus, the VP in (38) has no Pcorrespondent at all. Therefore, any constraint on the linear order of this VP relative to other elements is trivially fulfilled. Linearisation constraints like MAPhc do not evaluate whether there exists a correspondent, but only whether the existing correspondents are in a particular linear order. ${ }^{4}$

Take now the same structure with a full NP, for instance a proper name like 'Marit':

$$
\left[\mathrm{vP}_{\mathrm{Subj}} \mathrm{t}_{\mathrm{V}}[\mathrm{NP} \text { Marit }]\right]
$$

'Marit' is a lexical word, it has a word accent and therefore projects a prosodic word. This prosodic word now counts as correspondent of the whole VP. Thus, in this case VP has a P-correspondent! We will exploit this difference in our account of object shift introduced below.

The mapping from syntactic into prosodic structure is known to be imperfect. Constraints on this mapping have therefore often been stated as violable constraints. Truckenbrodt (1995) postulated the constraints StrEssXP and WrAPXP:

\footnotetext{
${ }^{4}$ Note, however, that the weak pronoun still counts as correspondent of its own NP, because it corresponds to its head.
} 
Constraints on syntax-prosody mapping: ${ }^{5}$

WrAP XP: Each lexically headed XP must be contained inside a $\phi$.

(Truckenbrodt 1995, 79)

Stress XP: Each lexically headed XP must contain a phrasal stress $x_{\phi}$. (Truckenbrodt 1995, 226)

In addition, alignment constraints like ALIGnPPh from (Selkirk 1996, see section

3) are very common in describing the "syntax" of prosodic domains.

For our analysis, the interaction of constraints of these two types is crucial:

a) linearisation of syntactic structure in the overt form

b) well-formedness of prosodic structure

Both constraint types evaluate properties of $\mathrm{P}$. This way, we are able to model the syntax-phonology interaction that we observed as the interaction of syntactic and prosodic constraints on linear order. The only prosodic structure constraint that we need for a start is Selkirk's (1996) AlignPPh.

\section{Object Shift in Danish and Swedish}

Our first analysis is concerned with Danish object shift. In particular, we need to derive the pattern illustrated in (8): If the verb has undergone verb second movement, a weak object pronoun moves in front of an adverb adjoined to VP, while a full NP remains behind the adverb. If the verb remains inside VP, OS is blocked.

Let us assume, in addition to ALIGNPPh, the two linearisation constraints MAPhc from Schmid and Vogel (2004), and the one in (41), and the ranking in $(42):^{6}$

AdjunctLeft (AdJL):

If $\mathrm{A}$ is adjoined to $\mathrm{B}$ at $\mathrm{S}$, then the correspondent of $\mathrm{A}$ precedes the correspondent of $\mathrm{B}$ at $\mathrm{P}$.

MAPhc $\gg$ AdJL $\gg$ AlignPPh

\footnotetext{
5 (40) cites the definitions as given in Truckenbrodt (1995), including the notational conventions used there: " $\phi$ " is the symbol used for the prosodic category "phonological phrase', and " $x_{\phi}$ " is the symbol for "head of a phonological phrase".

${ }^{6}$ Linearisation constraints like Headleft, HeadRight, Complementleft etc. are familiar from Jane Grimshaw's work in OT syntax (cf. Grimshaw 1997, a.o.). In Grimshaw's version of OT syntax, linearisation is defined on syntactic trees. But apart from this, the constraint system is to a large extent equivalent to ours. Zepter (2003) presents a more recent detailed application of Grimshaw's system in accounting for the typology of basic word order patterns.
} 
The high rank of MAPhc ensures that the relative order of head and complement is immune to prosodic triggers for reordering. ADJL now evaluates in our example the relative order of the negation and the VP it is adjoined to. If the VP contains only a weak pronoun, VP has no correspondent and ADJL is trivially fulfilled by any candidate. Thus, that constraint cannot decide among two rival candidates and the next lower constraint comes into play, AlignPPh.

(43) Weak pronoun OS in Danish:

\begin{tabular}{|c|c|c|c|}
\hline$\left[\ldots\left[\mathrm{VP}\right.\right.$ NEG $\left.\left.\left[\mathrm{VP} \mathrm{t}_{\mathrm{V}} \mathrm{PRO}_{w k}\right]\right]\right]$ & MAPhc & ADJL & AlignPPh \\
\hline $\begin{array}{r}\ldots \text { pro neg } \\
\ldots \text { neg pro }\end{array}$ & & & $* !$ \\
\hline
\end{tabular}

If the object is a full NP, the VP has a correspondent, and ADJL is crucially violated by the OS candidate, but there is no need to move the object anyway:

$$
\text { Prohibition of full NP OS in mainland Scandinavian: }
$$

\begin{tabular}{c|c|c|c}
\hline$\left[\ldots\left[\mathrm{VP}\right.\right.$ NEG $\left.\left.\left[\mathrm{VP} \mathrm{t}_{\mathrm{V}} \mathrm{NP}\right]\right]\right]$ & MAPhc & ADJL & AlignPPh \\
\hline$\ldots$ noun neg & & $* !$ & \\
nogeg noun & & & \\
\hline
\end{tabular}

If the verb remains in situ, a violation of ALIGNPPh is tolerated in order to fulfil the syntactic linearisation constraints.

(45) Prohibition of OS with V in situ in mainland Scandinavian:

\begin{tabular}{|c|c|c|c|}
\hline$\left[\ldots\left[\mathrm{VP}\right.\right.$ NEG $\left[\mathrm{VP}\right.$ V $\left.\left.\mathrm{PRO}_{w k}\right]\right]$ & MAPhc & ADJL & ALIGNPPh \\
\hline $\begin{array}{r}\text { a. ... neg pro } V \\
\text { b. ... neg V V pro } \\
\text { c. ... V V pro neg }\end{array}$ & $* !$ & $* !$ & * \\
\hline
\end{tabular}

Candidate (a.) violates MAPhc because the pronoun still counts as correspondent of NP and MAPhc requires V to precede NP. Candidate (c.) is also a possible repair, but it violates ADJL. Note that this tableau shows that ranking ALIGNPPh below the other two constraints is crucial. For the relative ranking of MAPhc and ADJL we in fact do not have crucial data. However, some observations about Swedish adverbs suggest that right-adjunction is possible, and that this constraint therefore might have lower priority:

(46) Adverbs on the right in Swedish (Broekhuis 2001, 696):
a. Han tvättar gärna
bilen
he washes with-pleasure the car 
b. Han tvättar bilen gärna

c. Han tvättar ju/inte bilen he washes indeed/not the car

d. *Han tvättar bilen ju/inte

The contrast between (46) and (45) shows that this phenomenon is dependent on adverb type. The negation is very frequently used to test for object shift, because it may not occur to the right of VP.

OS is also blocked for full NP objects and if the verb remains inside VP. However, we saw in the Swedish examples in (10), repeated in (47), that all other material within VP also blocks OS of weak pronouns:

Swedish, OS blocked $(=(10))$ :

a. *Jag talade henne $e_{i}$ inte med $t_{i}$

I spoke her not with

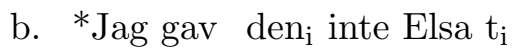

I gave it not Elsa

c. *Dom kastade mej $j_{i}$ inte ut $t_{i}$

They threw me not out

(Holmberg 1986; Sells 2001, 47f)

Example (47-a) is already covered by the constraint set we have thus far, in particular, MAPhc also applies to prepositional phrases and bans the pronoun from occuring left to the preposition. The same could be claimed for (47-c) under a head analysis for the particle. Sells (2001), for instance, argues that the particle is right-adjoined to the verb in Swedish particle verb constructions.

Example (47-b) requires a constraint that evaluates the relative order of the two NPs. Let us assume that 'Elsa' c-commands 'den'. Then a constraint that evaluates the relative order of NPs is sufficient here:

$\operatorname{MAP}(\mathrm{NP})$

If $\mathrm{A}$ c-commands $\mathrm{B}$ at $\mathrm{S}$, and $\mathrm{A}$ and $\mathrm{B}$ are NPs, then the correspondent of $\mathrm{A}$ precedes the correspondent of $\mathrm{B}$ at $\mathrm{P}$.

This constraint must be ranked higher than AlignPPh, perhaps on a par with MAPhc:

$$
\text { MAP(NP) MAPhc } \gg \text { AdJL } \gg \text { AlignPPh }
$$

\section{OS from non-final position}

Swedish particle verbs like the one illustrated in (47-c) are exceptional among mainland Scandinavian in that the particle precedes the object. Danish particle verbs have the object in front of the particle. Interestingly, weak object pronouns 
with particle verbs again have to shift:

(50) Danish:

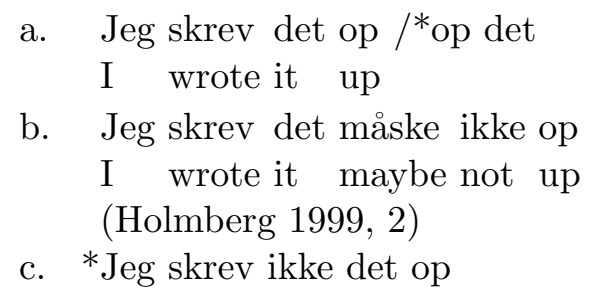

The problem posed by the contrast in $(50-\mathrm{b}, \mathrm{c})$ is: Why does the pronoun have to move in front of the negation, although it does not occupy a final position in a phonological phrase?

Consider example (50-c). What would be the prosodic structure of this clause? Adverbs typically project their own phonological phrase. Let us assume this as given for this example. The particle ' $o p$ ' bears a word accent, projects a prosodic word and also a phonological phrase. It is the final phonological phrase and also functions as head of the intonation phrase. For the weak pronoun, we have three possibilities: it may integrate into the $\mathrm{PPh}$ of the negation or the $\mathrm{PPh}$ of the particle, or it may project its own $\mathrm{PPh}$ :

$$
\begin{aligned}
& \text { Possible phrasings of }(50-\mathrm{c}) \\
& \text { a. } \quad\left((i k k e)_{\mathrm{Pwd}}\right)_{\mathrm{PPh}}(\text { det })_{\mathrm{PPh}}\left((o p)_{\mathrm{PWd}}\right)_{\mathrm{PPh}} \\
& \text { b. } \quad\left((i k k e)_{\mathrm{PWd}} \text { det }\right)_{\mathrm{PPh}}\left((o p)_{\mathrm{PWd}}\right)_{\mathrm{PPh}} \\
& \text { c. } \quad\left((i k k e)_{\mathrm{PWd}}\right)_{\mathrm{PPh}}\left(\operatorname{det}(o p)_{\mathrm{PWd}}\right)_{\mathrm{PPh}}
\end{aligned}
$$

None of these options is possible. How can this be derived? (51-a) is excluded for principal reasons: 'det' lacks word stress and cannot poject prosodic structure. (51-b) violates Selkirk's (1996) ALIGNPPh which bans weak function words from the right edge of phonological phrases. In (51-c), it occurs at the left edge of the final PPh. In Selkirk's system, the edges of prosodic layers are subject to a whole family of constraints, alignment constraints. There is no intrinsic reason, why the right edge should be more important than the left edge. Thus, it is very reasonable that AlignPPh comes in two versions, one for the left edge and one for the right edge:

(52) Phonological phrase alignment (cf. Selkirk 1996, 202):
a. $\quad \operatorname{Align}(\mathrm{PPh}, \mathrm{R} ; \mathrm{PWd}, \mathrm{R})(=\mathrm{AlignPPhR})$
b. $\quad \operatorname{Align}(\mathrm{PPh}, \mathrm{L} ; \mathrm{PWd}, \mathrm{L})(=\mathrm{AlignPPhL})$

Why is structure (50-b) preferred? The prosodic structure of this clause is presumably the one in (53):

$$
\left(\text { jeg }(\text { skrev })_{\mathrm{PWd}}\right)_{\mathrm{PPh}}\left(\text { det }(\text { ikke })_{\mathrm{PWd}}\right)_{\mathrm{PPh}}\left((\text { op })_{\mathrm{PWd}}\right)_{\mathrm{PPh}}
$$


It seems, thus, that a violation of ALIGNPPhL in a non-final $\mathrm{PPh}$ is less problematic than in the final $\mathrm{PPh}$. Recall that the final $\mathrm{PPh}$ is more prominent than the pre-final one, as it is the head of the intonation phrase. This asymmetry can be captured by two additional constraints that require edge alignment on PPhs which serve as heads, let us call them AlignPPhL $h d$ and AlignPPhR $h d$. The data just discussed suggest the following ranking for Danish and Swedish:

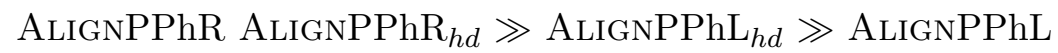

This ranking now makes the correct prediction: ${ }^{7}$

\begin{tabular}{|c|c|c|c|c|}
\hline [vP ikke [vP tV $\operatorname{det}$ op ]] & $\begin{array}{c}\text { ALIGN } \\
\mathrm{PPhR}_{h d}\end{array}$ & $\begin{array}{l}\text { ALIGN } \\
\text { PPhR }\end{array}$ & $\begin{array}{c}\text { ALIGN } \\
\text { PPhL }_{h d}\end{array}$ & $\begin{array}{l}\text { ALIGN } \\
\text { PPhL }\end{array}$ \\
\hline $\begin{array}{l}\text { a. (ikke) })_{\mathrm{PPh}}(\operatorname{det} \mathrm{op})_{\mathrm{PPh}} \\
\text { b. (ikke det })_{\mathrm{PPh}}(\mathrm{op})_{\mathrm{PPh}} \\
\text { c. (ikke) })_{\mathrm{PPh}}(\text { det })_{\mathrm{PPh}}(\mathrm{op})_{\mathrm{PPh}} \\
\text { d. (ikke) })_{\mathrm{PPh}}(\mathrm{op} \text { det })_{\mathrm{PPh}} \\
\text { d e. (det ikke) })_{\mathrm{PPh}}(\mathrm{op})_{\mathrm{PPh}}\end{array}$ & $* !$ & $\begin{array}{l}* ! \\
* ! \\
*\end{array}$ & $* !$ & $\begin{array}{l}* \\
* \\
*\end{array}$ \\
\hline
\end{tabular}

The ideal position for weak function words, according to this system of constraints, is between two prosodic words, avoiding the occurrence at either edge.

An alternative explanation for the data in (50) in terms of linearisation constraints is possible which exploits our guiding insight that weak pronouns do not take part in prosodic structure building. The constraints on linear order might not be restricted to requirements on the relative order of elements, but they might also require adjacency of elements of $\mathrm{P}$. Let us assume such a constraint for an adjunct and its host:

ADJADJ:

If $\mathrm{A}$ is adjoined to $\mathrm{B}$ at $\mathrm{S}$, then the correspondents of $\mathrm{A}$ and $\mathrm{B}$ are adjacent at $\mathrm{P}$.

This constraint has an interesting effect for our case of Danish particle verbs. The underlying structure for example $(50-\mathrm{b})$ is $(57-\mathrm{b})$ :

$$
\text { [IP jeg skrev [vP ikke [vP tV det op ]]] }
$$

The correspondent of the the adjunct is the prosodic word ' $i k k e$ '. The correspondent of the VP is only the prosodic word ' $o p$ ', the pronoun ' det' does not count. In order to have the two correspondents adjacent, the pronoun has to move out of the way. It may not move rightwards, because of ALIGNPPhR, so it moves leftwards. The tableau in (58) shows how this result is achieved, with ADJADJ and ADJL

\footnotetext{
${ }^{7}$ Note that candidate (55-c), where a weak pronoun has its own $\mathrm{PPh}$, is excluded independent of the constraint ranking. The candidates (b.) and (e.) have one violation less than (c.). Candidate (c.) is thus "harmonically bounded".
} 
ranked on a par.

$(58)$

\begin{tabular}{|c|c|c|c|}
\hline$\left[\mathrm{vP}\right.$ inte $\left[\mathrm{vP} t_{\mathrm{V}} \operatorname{det}\right.$ op $\left.]\right]$ & $\overline{\mathrm{ADJL}}$ & $\overline{A D J A D J}$ & $\overline{A L I G N P h P R}$ \\
\hline $\begin{array}{l}\text { a. ikke det op } \\
\text { b. ikke op det } \\
\text { c. det op ikke } \\
\text { d. det ikke op }\end{array}$ & $* !$ & $* !$ & $* !$ \\
\hline
\end{tabular}

Which of the two solutions is correct, is an empirical matter, and requires examination of a larger body of data than we can consider here. So I will leave this issue open.

Both approaches can account for other cases of clause-internal weak pronoun shift, as in the examples of weak subject pronouns in German and Swedish:

German subject pronouns $(=(5))$ :

a. Heute wird $*$ bestimmt es regnen $/ \sqrt{ }$ es bestimmt regnen today will certainly it rain/ it certainly rain

b. Dann hat *wohl er / er wohl gelogen

then has ${ }^{*}$ well he / he well lied

(60) Swedish subject pronouns $(=(6))$ :

Igår tog * inte han / han inte med sig sina pengar yesterday carried $* \overline{\text { not }} \overline{\text { he }} / \overline{\text { he }} \overline{\text { not }}$ with SELF his money

The explanation follows the same logic as before. In order to have the adverb and its host adjacent, the pronoun has to go out of the way. Alternatively, 'er', 'es' and 'han' have to leave the final phonological phrase and align with the left edge of the penultimate $\mathrm{PPh}$ to improve prosodic phrasing.

\section{Swedish pronouns}

Swedish seems to be much more liberal than Danish. While a weak object pronoun may remain in clause-final position, i.e., OS is only optional, the pronoun may also undergo "long object shift" across the subject, and occupy positions within a cluster of adverbs. None of these options is possible in Danish. However, it seems that there is a lot of dialectal variation in Swedish.

\subsection{Optionality of OS in Swedish}

With respect to the problem of optionality, recent observations reported by Josefsson (2003) suggest that the analysis presented here is on the right track.

She made a survey on the acceptability of shifted and non-shifted structures 
with weak pronouns among 29 Swedish native speakers. Speakers could give gradient judgements ranging from "OK" $=4$ points to "**" $=0$ points.

Josefsson does not present the exact figures of her survey. Her diagram only allows a guess for the approximated value which I present in (61):
a. $\quad$ Mannen såg inte den $\approx 3.0$
man.the saw not it
b. Mannen såg den inte $\approx 3.8$
c. Jag gillar inte honom $\approx 3.5$
I like him not
d. Jag gillar inte honom $\approx 3.8$

The unshifted version with the pronoun ' $d e n$ ' is obviously less acceptable than the shifted version and the unshifted version with 'honom'. Between the two versions with 'honom', the difference is rather small. Josefsson suggests that

"[...] the different opinions with regard to individual sentences seem to depend, at least partly, on the syllabic structure of the pronoun, perhaps also on other factors. [...]"

(Josefsson 2003, 202)

One difference between the two pronouns is that 'den' is monosyllabic while 'honom' is disyllabic. For Selkirk's account, it is crucial that the function words she deals with are monosyllabic. Disyllabic words usually have at least word stress. This might make it easier for them to project prosodic words, and allow them to occur clause-finally.

The pronunciation of function words is subject to much dialectal variation, and if this factor is crucial for object shift, we expect differences among dialects with respect to the possibility and optionality of OS quite frequently. That this is indeed the case has repeatedly been reported in the literature.

\subsection{Long object shift}

Typical examples of long object shift in Swedish - the only Scandinavian language that is proposed to have it - are given in (62):

(62) Long object shift (Josefsson 2003, 204):

a. I hallen mötte honom en hemsk syn in hall.the met him a horrible view "In the hall he met a terrible sight."

b. I det ögonblicket slog henne en skrämmande tanke in that moment hit her a terrifying thought "In that moment she was struck by a terrifying thought."

Josefsson (2003) notes that long OS is a challenge for Holmberg's generalisation. It assumes, in the version proposed by Holmberg (1999), that an adverb is 'invisible' 
in the sense that it does not block object shift. However, as other arguments, the verb, a particle or a preposition block OS it is assumed that adverbs are exceptional in this. That an object may move in front of a subject, is totally unexpected.

Josefsson notes that certain conditions must be met for long OS to apply. Animacy of the pronoun is one crucial factor. In (62), we have an animate object pronoun and an inanimate subject. Other examples of long OS given in the literature suggest that person might also be a factor:

a. Darför ger mig Tutanchamons hemska förbannelse ingen ro therefore gives me Tutankhamen's terrible curse no peace "Therefore Tutankhamen's terrible curse gives me no peace.'

b. Varför hjälper mig Helge ikke

Why helps me Helge not

"Why doesn't Helge help me?"

c. *Varför hjälper mig du ikke

Why help me you not

"Why don't you help me?"

(Josefsson 1992)

A first person object pronoun may occur in front of a third person subject, even an animate one, but not in front of a second person pronominal subject. Prominence scales like the person scale $\left(1^{s t}, 2^{\text {nd }}>3^{\text {rd }}\right)$ and the animacy scale (animate $>$ inanimate) figure prominently in recent typological work in Optimality Theory, starting with Aissen $(1999,2001)$ who shows how such functional scales guide phenomena like ergative split and the choice of passive voice. A third factor that might be relevant is the complexity of the subject NP. The examples in (62) as well as (63-a) use quite complex NPs as subjects. That lighter NPs precede heavier NPs is a general tendency which is well-known from word order regularities in the middle field of the German clause (see Vogel and Steinbach 1998; Müller 1999, and references cited there), as well as from English Heavy NP shift.

A cumulation of these factors obviously makes long OS across the subject more likely. Without going into detail, an OT account should be capable of modelling this, along the lines of Aissen (1999) and Müller (1999), and it should be possible to integrate this with what we have thus far. However, as long OS is an optional process, the empirical reality of this operation needs to be clarified first. Which are the conditions under which it applies, is it the unmarked option, when it is grammatical, and how frequent is it? A more detailed exploration of these issues goes beyond the scope of this paper. 


\subsection{Adverbial intermingling}

Swedish is also exceptional in allowing weak pronouns to occur within a sequence of adverbs. This is called "adverbial intermingling". The weak pronoun may occur in each of the indicated positions in Swedish:

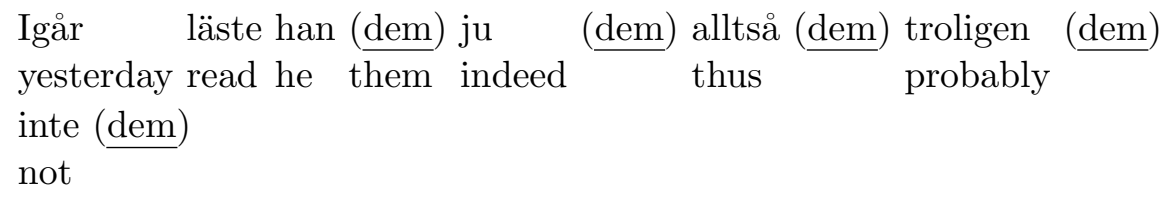

(Hellan and Platzack 1995, 56).

Danish requires the pronoun to precede all adverbs. This can be attributed to the constraint ADJADJ in our system. Each adverbial adjunct is part of the host of the next higher adjunct. In order to yield adjacency of host and adjunct, the pronoun has to move out of the way, to the left of the adverbial cluster. This will lead to a violation of AlignPPhL, however. In Swedish, these two constraints might be equally ranked. Having a weak pronoun between two adverbs is advantageous in those cases where the adverbs do not all project phonological phrases:

$$
\left(\left(\text { adverb }_{1}\right)_{\text {PWd }} \text { pronoun }\left(\text { adverb }_{2}\right)_{\text {PWd }}\right)_{\text {PPh }}
$$

The pronoun does not align with an edge of a $\mathrm{PPh}$ here, and so no violation of the $\mathrm{PPh}$ alignment constraints is incurred. Especially those adverbs which are prosodically rather weak, like ' $j u$ ' might be candidates for such structures. Again, we expect much inter-speaker and dialectal variation.

\subsection{OS across the particle}

Another interesting paradigm has first been discussed by Vinka (1999). Swedish particle verbs differ in the predicative status of the particle. Predicative particles are those which have a transparent contribution to the meaning of the clause, i.e., in (66), when the TV is turned on, we can say that the TV is on. Other verbs with a non-predicative particle, like ' $n e r$ ' in (67), do not allow OS across the particle.

(66) OS across a predicative particle:

a. Kalle satte på den

Kalle sat on it

'Kalle switched it on'

b. Kalle satte den på

c. *Kalle satte TVn på Vinka (1999) 
No OS across a non-predicative particle:

a. Kalle smutsade ner den

Kalle dirtied down it

b. *Kalle smutsade den ner

Vinka (1999)

The paradigm in (66) shows the characteristics of Swedish object shift, a full NP may not shift, while a weak pronoun may shift. Predicative particles are no intervenors in the sense of Holmberg's generalisation, while non-predicative ones are. Thus, a different syntactic analysis of the two is indicated. Let us assume that non-predicative particles are adjuncts to $\mathrm{V}^{0}$, while predicative particles are predicates in a small clause structure:

$$
\begin{array}{ll}
\text { a. } & \text { Predicative particles: } \\
& {[\mathrm{vP} V[\mathrm{SC} \text { Prt NP }]]} \\
\text { b. } & \text { Non-predicative particles: } \\
& {\left[\mathrm{VP}\left[\mathrm{V}^{0} \mathrm{~V} \text { Prt }\right] \mathrm{NP}\right]}
\end{array}
$$

Thus, non-predicative particles count as correspondents of $\mathrm{V}$ at $\mathrm{P}$, and the relative order of particle and NP is therefore subject to the highly ranked constraint MAPhc. Small clauses, on the other hand, have a special syntactic status, and need their own linearisation constraint, call it MAPsc:

MAPsc:

If $\mathrm{A}$ is the predicate of a small clause at $\mathrm{S}$, and $\mathrm{B}$ its subject, then the correspondent of A precedes the correspondent of $\mathrm{B}$ at $\mathrm{P}$.

The optionality of OS with a predicative particle verb now follows if MAPsc and AlignPPhR are tied. ${ }^{8}$ The pronoun in final position leads to a violation of ALIGNPPhR, while the pronoun in front of the particle violates MAPsc. A full NP in final position does not violate ALIGNPPhR, this order also satisfies MAPsc, and so the order 'full NP - particle' is blocked.

\section{English object shift}

The data in (70) show that English also avoids clause-final weak pronouns, if this is possible:

English weak pronoun shift $(=(3))$ :

a. I gave up the plan $/ *_{\text {it }}$

\footnotetext{
${ }^{8}$ I assume a global constraint tie here, which means that there are two co-grammars which differ in the relative rank of the two tied constraints. I.e., in one grammar MAPsc is higher, preferring 'particle pronoun' order, and in the other ALIGNPPhR is higher, favouring 'pronoun particle' order.
} 
b. I gave the plan/it up

c. I gave the book/it to Mary

d. I gave Mary the book/*it

The dative alternation in $(70-\mathrm{c}, \mathrm{d})$ is an instance of syntactic alternation. I briefly mentioned above that for such alternations the OT concept of faithfulness is quite useful. The idea is, roughly, that a particular syntactic structure that we want to express, i.e., that we have specified in the input, is neutralised to another closely related structure due to markedness. Faithfulness constraints ensure that the winning structure differs minimally from the input. We will only use a general version of the constraint and call it FAITH-SYN. It is ranked below AlignPPhR. Both are ranked below MAPhc, however, so in an ordinary transitive clause the pronoun has to remain behind the verb even if this means being in clause-final position. But as long as both candidates fulfil MAPhe, as in our examples in (70), AlignPPhR is decisive.

$(71)$

\begin{tabular}{l|c|c|c}
\hline She saw it & MAPhc & AlignPPhR & FAITH-SYN \\
\hline $\begin{array}{l}\text { She saw it } \\
\text { She it saw }\end{array}$ & $* !$ & $*$ & $*$ \\
\hline I gave Mary it & & & $*$ \\
\hline $\begin{array}{l}\text { I gave Mary it } \\
\text { I gave it to Mary }\end{array}$ & $* !$ & $*$ \\
\hline She gave up it & & & $*$ \\
\hline $\begin{array}{l}\text { She gave up it } \\
\text { She gave it up }\end{array}$ & & $* !$ & $*$ \\
\hline
\end{tabular}

\section{Conclusion}

A prosodic account offers a new perspective on Scandinavian weak pronoun object shift. It assumes that the phenomenon is due to a prosodic restriction which is quite common among the Germanic languages and among different kinds of function words. A purely phonological account fails as long as it lacks an integration of the syntactic factors that restrict object shift. The OT model developed in this paper integrates syntactic and prosodic constraints as constraints on the linear order of elements.

The most important assumption that has been made here is that weak function words are partly 'invisible' - they do not count as part of the correspondent of a verb phrase. This is due to their inability to project prosodic structure. Therefore, a shifted weak pronoun does not violate syntactic constraints on the linearisation of $\mathrm{VP}$, as long as it is leftmost within VP. On the contrary, adjacency conditions even 
require weak pronouns to move out of the way under particular circumstances.

This view of the phenomenon sharply contrasts with previous analyses of object shift like the one by Holmberg (1999). For Holmberg, an adverb is 'invisible' in the sense that it does not block object shift, unlike verbs, particles, predicates and arguments. The trigger for OS, according to Holmberg, is a feature $[ \pm$ Foc $]$, the content of which is not very clear.

I argued here that it is the other way around. From the perspective of prosody, it is the adverb which is 'visible', and the pronoun which seems to disappear. The pronoun's deficient prosody has two effects. One is the trigger for object shift, it tends to be removed from the right (and left) edge of a phonological phrase. Second, as mentioned above, it is unable to be the correspondent of syntactic phrases other than its own NP at the surface representation P. For a VP containing a weak pronoun, it is as if the pronoun was not there at all. Therefore, a VP-adverb can change its place with a pronoun without even violating the syntactic constraint on the linearisation of adjuncts.

The major advantage of this approach is its empirical adequacy and coverage: it focuses on the prosodic weakness of the pronoun as the driving force behind object shift, and generalises to related phenomena with different function words and in different Germanic languages.

\section{References}

Aissen, Judith (1999). 'Markedness and Subject Choice in Optimality Theory.' In Legendre $\mathscr{E}$ al. (2001).

- (2001). 'Markedness and Subject Choice in Optimality Theory.' In Legendre Es al. (2001).

Bobaljik, Jonathan (1995). Morphosyntax: The syntax of verbal inflection. Ph.D. thesis, MIT, Cambridge, Massachusetts.

Bobaljik, Jonathan David (2002). 'A-Chains at the PF-Interface: Copies and Covert Movement.' Natural Language and Linguistic Theory 20:197-267.

Broekhuis, Hans (2001). 'Aganist Feature Strength: The Case of Scandinavian Object Shift.' Natural Language and Linguistic Theory 18:673-721.

Chomsky, Noam (1993). 'A minimalist program for linguistic theory.' In Hale, Kenneth and Samuel J. Keyser, eds., The view from Building 20: Essays in linguistics in honour of Sylvain Bromberger, pp. 1-52. Cambridge, Massachusetts: MIT Press.

Diesing, Molly (1992). Indefinites. Cambridge, Massachusetts: MIT Press.

Erteschik-Shir, Noemi (2002). 'P-syntactic Motivation for Movement: Imperfect Alignment in Object Shift.' Working Papers in Scandinavian Syntax (68):49-73. 
Gärtner, Hans-Martin and Markus Steinbach (2001). 'What do reduced pronominals reveal about the syntax of Dutch and German?' Linguistics in Potsdam 9:7-62.

Grimshaw, Jane (1997). 'Projection, Heads and Optimality.' Linguistic Inquiry 28:373-422.

Hellan, Lars (1994). 'On pronominal clitics in Norwegian.' In Hedlund, C. and A. Holmberg, eds., Proceedings of the XIVth Scandinavian Conference of Linguistics. Special Session on Scandinavian Syntax, pp. 1-14. Gothenberg: University of Gothenberg.

Hellan, Lars and Christer Platzack (1995). 'Pronouns in Scandinavian Languages: An Overview.' Working Papers in Scandinavian Syntax 56:47-69.

Holmberg, Anders (1986). Word Order and Syntactic Features in the Scandinavian Languages and English. Ph.D. thesis, University of Stockholm, Department of General Linguistics.

— (1999). 'Remarks on Holmberg's Generalization.' Studia Linguistica 53(1):1-39.

Holmberg, Anders and Christer Platzack (1995). The role of inflection in Scandinavian syntax. Oxford and New York: Oxford University Press.

Josefsson, Gunlög (1992). 'Object Shift and Weak Pronominals in Swedish.' Working Papers in Scandinavian Syntax (49):59-94.

- (2003). 'Four myths about Object Shift in Swedish - and the Truth ...' In Delsing, Lars-Olof, ed., Grammar in Focus II. Festschrift for Christer Platzack, pp. 199-207. Lund: Wallin + Dalholm.

Kayne, Richard (1994). The Antisymmetry of Syntax. Cambridge, Massachusetts: MIT Press.

Legendre, Geraldine, Jane Grimshaw, and Sten Vikner, eds. (2001). Optimality Theoretic Syntax. Cambridge/Mass.: MIT Press.

McCarthy, John (1991). 'Synchronic rule inversion.' In Sutton, L. A., C. Johnson, and R. Shields, eds., Proceedings of the 17th Annual Meeting of the Berkeley Linguistics Society, pp. 192-207. Berkeley: Berkeley Linguistics Society.

- (1993). 'A case of surface constraint violation.' Canadian Journal of Linguistics/Revue canadienne de Linguistique 38:169-195.

Müller, Gereon (1999). 'Optimality, Markedness, and Word Order in German.' Linguistics (37):777-818. 
Schmid, Tanja and Ralf Vogel (2004). 'Dialectal Variation in German 3-VerbClusters. A Surface-oriented OT account.' Journal of Comparative Germanic Linguistics pp. 235-274.

Selkirk, Elisabeth (1996). 'The Prosodic Structure of Function Words.' In Morgan, James and Katherine Demuth, eds., Signal to Syntax: Bootstrapping from Speech to Grammar in Early Acquisition, pp. 187-213. Mahwah, New Jersey: Lawrence Erlbaum Associates.

Sells, Peter (2001). Structure, Alignment and Optimality in Swedish. Stanford Monographs in Linguistics. Stanford: CSLI Publications.

Truckenbrodt, Hubert (1995). Phonological Phrases: Their Relation to Syntax, Focus, and Prominence. Ph.D. thesis, MIT, Cambridge, Massachusetts.

- (1999). 'On the Relation between Syntactic Phrases and Phonological Phrases.' Linguistic Inquiry 30:219-255.

Vikner, Sten (1994). 'Scandinavian object shift and West Germanic scrambling.' In Corver, Norbert and Henk van Riemsdijk, eds., Studies on Scrambling, pp. 487-517. Berlin: Mouton de Gruyter.

- (1995). Verb Movement and Expletive Subjects in the Germanic Languages. Oxford Studies in Comparative Syntax. Oxford: Oxford University Press.

- (2001). 'The Interpretation of Object Shift and Optimality Theory.' In Müller, Gereon and Wolfgang Sternefeld, eds., Competition in Syntax, vol. 49 of Studies in Generative Grammar, pp. 321-340. Berlin: Mouton de Gruyter.

Vinka, Mikael (1999). 'Predicative and non-predicative verb-particle constructions.' In Bird, S., A. Carnie, J. Haugen, and P. Norquest, eds., Proceedings of WCCFL 18, pp. 570-585. Somerville, Massachusetts: Cascadilla Press.

Vogel, Ralf (2004). 'Remarks on the architecture of OT Syntax.' In Blutner, Reinhard and Henk Zeevat, eds., Optimality Theory and Pragmatics, pp. 211227. Houndmills, Basingstoke, Hampshire: Palgrave/Macmillan.

- (to appear). 'Correspondence in OT Syntax and Minimal Link Effects.' In Stepanov, Arthur, Gisbert Fanselow, and Ralf Vogel, eds., Minimality Effects in Syntax. Berlin: Mouton de Gruyter.

Vogel, Ralf and Markus Steinbach (1998). 'The Dative - an Oblique Case.' Linguistische Berichte 173:65-90.

Zepter, Alexandra (2003). Phrase Structure Directionality: Having a few Choices. Ph.D. thesis, Rutgers University, New Brunswick, NJ. 